\title{
A Correlative Study of the Influence of Higher Vocational Students' Learning Behavior on English Effective Learning
}

\author{
Lei Chen ${ }^{\mathrm{a}}$, Xia Liu ${ }^{\mathrm{a},}$, and Qinghui Zhu ${ }^{\mathrm{b}}$ \\ ${ }^{a}$ Sanya Aviation and Tourism College, Sanya, 572000, China \\ ${ }^{b}$ College of Foreign Languages, Hainan University, Haikou, 570228, China
}

\begin{abstract}
This study aims to explore the correlation between learning behavior and English effective learning. 1,758 answers to a questionnaire designed from the perspective of learning behavior are analyzed. The influence of English effective learning is summarized as constructive learning and destructive learning. Using SPSS to analyze the data and model a construction, we study the correlation between learning behavior and the main influencing factors, including constructive learning, destructive learning, mutual influence, learning burnout and employment pressure. The structural model results show that the alpha coefficients are above 0.6, and the corresponding variables load factor values are above 0.3 , which proves that the questionnaire is valid and reliable. Correlation analysis is used to explore the impact of the major variables, indicating that significant correlations exist among the major variables. The regression analysis shows that constructive learning can significantly predict the learning behavior, while the destructive behavior can significantly negatively predict the learning behavior. The mutual influence cannot significantly predict the learning behavior. Through a structural equation model fitting analysis, the influence of classmates can significantly predict the learning behavior and employment pressure can significantly negatively predict the learning burnout. Furthermore, learning behavior plays an intermediary role in constructive learning, destructive learning and learning burnout. This study may provide reference for higher vocational English teaching reform from the data analysis.
\end{abstract}

Keywords: constructive learning; destructive learning; effective learning; learning behavior

(Submitted on January 18, 2018; Revised on March 5, 2018; Accepted on April 15, 2018)

(C) 2018 Totem Publisher, Inc. All rights reserved.

\section{Introduction}

According to Ming Qinghua and Gu Murong [1], "Effective Learning should be considered from the learning agent. It is the occurrence of learning behavior". The purpose of learning is to be based on needs for survival, peer competition, individual interests, life ideal and target implements. Therefore, effective learning is not only for acquiring knowledge and the ability to solve problems, but also for cultivating the spirit of innovation so as to make people invincible in various social competitions $[4,7]$. There are many factors that affect effective learning, including internal factors such as learning behaviors and intellectual factors, as well as external factors such as learning environment, teacher quality and peer influence. One of the main goals of the vocational college students' English effective learning is to cultivate the students' English application ability, enhance the awareness of intercultural communication and communication skills, develop autonomous learning, improve the comprehensive cultural quality, as well as to use English effectively to meet the needs of the state and society, school and personal development [5]. Through effective learning, learning efficiency and learning effect are improved and strengthened. Learning behavior plays an important role in English learning effectiveness for higher vocational students. In many years of English teaching practice, we have paid much attention to language factors, such as English grammar, word pronunciation, and collaborative skills, but have neglected the important role of learning behavior in English effective learning. In order to reveal the positive and negative effects of learning behavior in English effective learning, we investigate the related problems that affect the effective learning, analyze the correlation and influence, and then promote the reform and development of English teaching in higher vocational education.

\footnotetext{
* Corresponding author.

E-mail address: $13258514 @ \mathrm{qq} . c 0 m$
} 


\section{Core concepts}

\subsection{SPSS}

SPSS Statistics is a software package used for logical batched and non-batched statistical analysis. The software name originally stood for Statistical Package for the Social Sciences, reflecting the original market even though the software is now popular in other fields as well, including the health sciences and marketing. SPSS is a widely used program for statistical analysis in social science. It is also used by market researchers, health researchers, survey companies, government, education researchers, marketing organizations, data miners, and others. The original SPSS manual (Nie, Bent \& Hull, 1970) has been described as one of "sociology's most influential books" for allowing ordinary researchers to do their own statistical analysis.

\subsection{Learning Behavior}

Learning Behavior emphasizes the crucial link between the way in which children and young people learn and their social knowledge and behavior. In doing this, the focus is upon establishing positive relationships across three elements: self, others and curriculum. The principles of learning behavior have wide ranging implications for pupils, teachers, parents and other professionals. The principles can be applied to all students at any age and not just those perceived as being "difficult to manage". They apply as much to teachers and their relationship with students as much as they do to the students themselves.

\subsection{Effective Learning}

Effective learning is the ability to successfully achieve the desired goals and good learning outcomes. Effective learning contains three aspects: learning outcomes, learning utility and learning efficiency. Therefore, in order to achieve the goal of effective learning, the three elements must be organically integrated and inherently unified in the learning process. The basic goal of effective learning is the acquisition of knowledge and ability. The ultimate goal is to enable students to get the right development.

Compared with learning in the general sense, effective learning has five salient features. The first is to set goals for students before teaching. It enables them to learn with a clear purpose and accomplish their intended goals. Second, in order to improve learning efficiency, students are asked to complete the scheduled learning objectives in a limited period of time. Third, generating is the most obvious trait for students to learn effectively. Fourth, in order to achieve the all-around development of students as the ultimate goal, the main body of the learning process is the student; the teacher only acts as a guide. Lastly, to achieve effective learning, students are required to communicate with each other. Effective learning pursues the most optimized learning, which is a process of wisdom generation.

\section{Meaning of Effective Learning}

The purpose of effective learning is to construct a self-education model for students to master knowledge effectively and get all-around progress and growth. Effective learning is the need of individual growth and social development. It is an important goal of education reform and a precondition and ultimate goal of education success. The study of effective learning is a rational path to promote the continuous development of teaching reform in the context of the new curriculum reform. It will promote the professional development of teachers and improve student learning ability and overall quality, so as to achieve high quality and balance of higher education in our country.

\section{Factors Influencing Students' Effective Learning}

Scholars have different theoretical explanations and divisions on the factors that affect the effective learning of students. The author mainly analyzes the influencing factors of effective learning from aspects of internal factors and external factors.

\subsection{Internal Factors}

Motivation encourages people to generate interest from a lack of interest. The motivation of the learner, that is, the driving force of the learner himself, is an important condition for effective learning. It is an important psychological factor that affects the learning process. It is also a psychological predisposition to cause and maintain individual learning behavior to meet learning needs. It is also a basic precondition to promote effective learning. 
Table 1. Frequency Statistical Table

\begin{tabular}{|c|c|c|c|}
\hline & & Frequency & Percentage $(\%)$ \\
\hline \multirow{2}{*}{ Sex } & Male & 911 & 51.80 \\
\hline & Female & 847 & 48.20 \\
\hline \multirow{2}{*}{ Grade } & Freshman & 1319 & 75.00 \\
\hline & Sophomore & 439 & 25.00 \\
\hline \multirow{5}{*}{ Learning purposes } & Meeting parents' expectation & 15 & 0.90 \\
\hline & Studying for work & 832 & 47.30 \\
\hline & $\begin{array}{c}\text { Acquiring higher vocational education } \\
\text { diploma }\end{array}$ & 97 & 5.50 \\
\hline & Studying for self-improvement & 768 & 43.70 \\
\hline & No specific purpose & 46 & 2.60 \\
\hline \multirow{6}{*}{ Learning objectives } & Passing examinations & 187 & 10.60 \\
\hline & Winning a scholarship & 125 & 7.10 \\
\hline & Mastering professional knowledge & 504 & 28.70 \\
\hline & Enhancing professional skills and abilities & 306 & 17.40 \\
\hline & Fulfilling one's potential & 115 & 6.50 \\
\hline & Find a decent job & 521 & 29.60 \\
\hline \multirow{7}{*}{$\begin{array}{l}\text { Reasons for choosing one's } \\
\text { major }\end{array}$} & Personal interest & 586 & 33.30 \\
\hline & Good employment prospects & 663 & 37.70 \\
\hline & Parents' suggestions & 212 & 12.10 \\
\hline & Reallocation & 94 & 5.30 \\
\hline & Less competition & 56 & 3.20 \\
\hline & Admission being the first priority & 44 & 2.50 \\
\hline & Requirement of society & 103 & 5.90 \\
\hline \multirow{5}{*}{ Way of learning in class } & Total reliance on teachers'lecture & 797 & 45.30 \\
\hline & Learning with questions & 344 & 19.60 \\
\hline & Focusing on key points only & 497 & 28.30 \\
\hline & Self-study & 50 & 2.80 \\
\hline & Being absentminded & 70 & 4.00 \\
\hline \multirow{5}{*}{ After-hours } & Studying & 258 & 14.70 \\
\hline & Involving in romantic relationship & 95 & 5.40 \\
\hline & Recreational and sports activities & 371 & 21.10 \\
\hline & $\begin{array}{l}\begin{array}{l}\text { Surfing the Internet, playing computer } \\
\text { games }\end{array} \\
\text {. }\end{array}$ & 325 & 18.50 \\
\hline & Others & 709 & 40.30 \\
\hline \multirow{3}{*}{ Reasons for skipping class } & Disliking attending classes & 260 & 14.80 \\
\hline & Handling other matters & 1403 & 79.80 \\
\hline & Disliking teachers & 95 & 5.40 \\
\hline \multirow{5}{*}{ Reasons for attending classes } & $\begin{array}{l}\text { Contents learned in classes being } \\
\text { interesting,inspiring and rewarding,being } \\
\text { able to boost students'confidence }\end{array}$ & 624 & 35.50 \\
\hline & Teachers being competent & 556 & 31.60 \\
\hline & $\begin{array}{l}\text { Under the influence of high-achieving } \\
\text { students }\end{array}$ & 149 & 8.50 \\
\hline & Multimedia teaching means & 136 & 7.70 \\
\hline & No specific reason & 293 & 16.70 \\
\hline \multirow{9}{*}{ Reasons for disliking study } & Weak study basis & 431 & 24.50 \\
\hline & Unproductive in class & 104 & 5.90 \\
\hline & Classes being boring & 308 & 17.50 \\
\hline & No multimedia teaching means & 12 & 0.70 \\
\hline & Inefficient learning methods and plans & 284 & 16.20 \\
\hline & $\begin{array}{c}\text { Poor self-study abilities (poor memory, } \\
\text { concentration and weak comprehensive } \\
\text { ability, etc.) }\end{array}$ & 262 & 14.90 \\
\hline & $\begin{array}{l}\text { Contents learned in classes being too } \\
\text { difficult, lack of self-confidence }\end{array}$ & 129 & 7.30 \\
\hline & Being nervous around teachers & 22 & 1.30 \\
\hline & No specific reason & 206 & 11.70 \\
\hline
\end{tabular}

Another important internal factor is learning interest. According to Herbart, the main interest is the correct and comprehensive understanding of objects, which promotes the long-term preservation of knowledge and offers motivation for further learning. Student interest in learning is the tendency to seek something or engage in a certain activity with a strong emotional color. Learning interest is an important aspect for students to learn positively and also a "starting point" for talent 
growth. Designing an effective learning environment can push effective learning further into practice, and a well-designed learning environment can be an important guarantee for the effectiveness of student learning. A good learning environment can provide students with a good mood, which is a necessary condition for students to learn effectively. Therefore, it is necessary to create a relaxed learning atmosphere for students, thereby stimulating the creativity of students. In such a teaching environment, the students' subjectivity has been taken seriously. The learning style is vivid and fun. Students have a good emotional experience, which can satisfy student learning needs, strengthen student learning activities, maintain the desire to learn, and ultimately promote effective learning.

\subsection{External Factors}

Here, we mainly discuss mutual influence and the learning environment. Cooperative learning by groups allows students to take initiative to learn from each other in a positive and progressive atmosphere. It cultivates good habits in which students are willing to look for regularities and think about problems comprehensively. Through mutual discussion and exchange among members, students can take the initiative to think about problems and make positive statements. In this environment, the sense of teamwork is strengthened, student unity and cooperation is cultivated, students are actively involved in cooperation and competition, and their expertise and wisdom can be fully utilized, thereby enhancing student learning efficiency.

\section{Research Design}

\subsection{Research Problem}

This study solves three main problems: First, what are the learning behaviors in the process of English learning in higher vocational colleges? Second, what is the relationship between learning behavior (constructive learning and destructive learning) [3] and these factors (learning behavior, learning burnout, mutual influence, and employment pressure)? Third, how do these factors work together to influence English effective learning?

\subsection{Research Object}

In this study, a sample survey was conducted with students in higher vocational colleges in Hainan Province. There were 1758 valid samples, of which 911 were male and 847 were female.

As shown in Table 1, the number of students who "study for work" and "study for self-improvement" are the highest, accounting for $47.3 \%$ and $43.7 \%$ respectively. Among the learning objectives, the number of students who take "finding a decent job" and "mastering professional knowledge" as the learning target are the highest, accounting for $29.6 \%$ and $28.7 \%$ respectively. Among the reasons for choosing one's major, the number of students who choose their major because of "good employment prospects" and " personal interests" are the highest, accounting for $37.7 \%$ and $33.3 \%$ respectively. In the way of learning in classes, the number of students who are "totally reliant on teachers' lectures" and "focus on key points only" are the highest, accounting for $45.3 \%$ and $28.3 \%$ respectively. During the after-hours, $40.3 \%$ of students chose "others", which is the highest number. Among the reasons for skipping classes, the number of students who skip classes to "handle other matters" is the highest, accounting for $79.8 \%$. Among the reasons for attending classes, the number of students who find "contents learned in classes being interesting, inspiring and rewarding and being able to boost students' confidence" and "teachers being competent" are the highest, accounting for $35.5 \%$ and $31.6 \%$ respectively. Among the reasons for disliking studying, the number of students who believe "weak study basis", "classes being boring", "inefficient learning methods and plans" and "poor self-study abilities (poor memory, concentration and weak comprehensive ability, etc.)" to be the majors reasons are the highest, accounting for $24.5 \%, 17.5 \%, 16.2 \%$ and $14.9 \%$ respectively.

\subsection{Questionnaire Design and Data Analysis}

The questionnaire mainly consists of 2 parts and a total of 37 questions: The first part is the personal information of the student (gender, grade, province, professional choice, etc.). In the second part, we design the subject mainly from the learning behavior in order to test its impact on English effective learning. We divide the problems into two types: constructive learning and destructive learning, and we study the interaction among learning behavior, learning burnout [6], employment pressure and mutual influence. All the valid questionnaires collected were input into software SPSS 21.0, and the measurement models of each subscale were established by using Amos21.0. The data were described by statistics, difference test, reliability and validity test, correlation regression and so on. The structural equation model was used to fit the main research variables [2]. 


\section{Results and Discussion}

\subsection{Difference Test}

An independent sample t-test is used to analyze the gender differences in each of the major study variables. The results (Table 2) showed that the scores of destructive learning in boys $(\mathrm{M}=2.589, \mathrm{SD}=0.733)$ are significantly lower than those in girls $(\mathrm{M}=2.671, \mathrm{SD}=0.684)$, but boys $(\mathrm{t}=4.819, \mathrm{p}<0.01 ; \mathrm{t}=2.352, \mathrm{p}<0.05)$ are significantly higher than those of girls $(\mathrm{M}=0.19, \mathrm{SD}=0.39 ; \mathrm{M}=0.16, \mathrm{SD}=0.37)$ in learning burnout and mutual influence. There are no significant gender differences in other research variables $(\mathrm{t}=-1.083 . \mathrm{p}>0.05 ; \mathrm{t}=0.483 . \mathrm{p}>0.05 ; \mathrm{t}=-1.832 . \mathrm{p}>0.05)$. Destructive learning in class such as playing with cell-phones, being late, skipping classes, etc. is less apparent in boys compared to girls, but learning burnout and mutual influence have a higher impact on boys than girls. The impact on English learning on boys and girls is the same in the aspect of constructive learning and employment pressure.

Table 2. Analysis of gender differences in major research variables

\begin{tabular}{|c|c|c|c|c|c|c|}
\hline & \multicolumn{2}{|c|}{ Male $(\mathrm{N}=911)$} & \multicolumn{2}{|c|}{ Female $(\mathrm{N}=847)$} & \multirow{2}{*}{$\mathrm{t}$} \\
\cline { 2 - 6 } & $\mathrm{M}$ & $\mathrm{SD}$ & $\mathrm{M}$ & $\mathrm{SD}$ & \\
\hline Constructive Learning & 2.119 & 0.636 & 2.15 & 0.556 & -1.083 & 0.279 \\
\hline Destructive Learning & 2.589 & 0.733 & 2.671 & 0.684 & -2.402 & 0.016 \\
\hline Learning behavior & 1.796 & 0.445 & 1.786 & 0.41 & 0.483 & 0.629 \\
\hline Learning burnout & 0.28 & 0.451 & 0.19 & 0.39 & 4.819 & 0.000 \\
\hline Mutual influence & 0.21 & 0.405 & 0.16 & 0.37 & 2.352 & 0.019 \\
\hline Employment pressure & 0.44 & 0.496 & 0.48 & 0.5 & -1.832 & 0.067 \\
\hline
\end{tabular}

Independent sample t-test is used to analyze the major research variables in different grades. The results in Table 3 show that freshmen scores $(M=2.103, \mathrm{SD}=0.588 ; \mathrm{M}=1.710, \mathrm{SD}=0.370 ; \mathrm{M}=0.220, \mathrm{SD}=0.416 ; \mathrm{M}=0.440, \mathrm{SD}=0.496$ ) are significantly lower than those of sophomores ( $M=2.225, \mathrm{SD}=0.622 ; \mathrm{M}=2.033, \mathrm{SD}=0.0 .496 ; \mathrm{M}=0.280$, $\mathrm{SD}=0.448 ; \mathrm{M}=0.510, \mathrm{SD}=0.500)$ in constructive learning, learning behavior, learning burnout and employment stress ( $\mathrm{t}=-3.705, \mathrm{p}<0.01 ; \mathrm{t}=-12.531, \mathrm{p}<0.01 ; \mathrm{t}=-2.265, \mathrm{p}<0.05 ; \mathrm{t}=-2.590, \mathrm{p}<0.05)$. There is no significant difference in the grades of other research variables $(t=1.114 . p>0.05 ; t=0.341 . p>0.05)$. This indicates that the freshmen had a better learning attitude than sophomores because they were unfamiliar with the school and there was no employment pressure. In terms of constructive learning, learning burnout and employment pressure on English effective learning, freshmen scores were significantly lower than sophomores.

Table 3. Analysis of the major research variables in different grades

\begin{tabular}{|c|c|c|c|c|c|c|}
\hline \multirow{2}{*}{ Variables } & \multicolumn{2}{|c|}{ Freshmen $(\mathrm{N}=1319)$} & \multicolumn{2}{|c|}{ Sophomores $(\mathrm{N}=439)$} & $\mathrm{t}$ & $\mathrm{p}$ \\
\cline { 2 - 7 } & $\mathrm{M}$ & $\mathrm{SD}$ & $\mathrm{M}$ & $\mathrm{SD}$ & & 0.3 .705 \\
\hline Constructive Learning & 2.103 & 0.588 & 2.225 & 0.622 & 000 \\
\hline Destructive Learning & 2.639 & 0.710 & 2.596 & 0.714 & 1.114 & 0.265 \\
\hline Learning Behavior & 1.710 & 0.370 & 2.033 & 0.496 & -12.531 & 0.000 \\
\hline Learning Burnout & 0.220 & 0.416 & 0.280 & 0.448 & -2.265 & 0.024 \\
\hline Mutual Influence & 0.190 & 0.390 & 0.180 & 0.385 & 0.341 & 0.733 \\
\hline Employment Pressure & 0.440 & 0.496 & 0.510 & 0.500 & -2.590 & 0.010 \\
\hline
\end{tabular}

\subsection{Reliability and Validity Test}

The GFI, AGFI and CFI in Table 4 are above 0.93. It is generally considered that all the above indexes are greater than 0.9 , indicating that the model is well-fitted. The RMSEA is less than 0.08, and the RMR is less than the critical value of 0.05 . The structural validity of constructive learning, destructive learning and learning behavior obtained in this research is good.

Alpha Reliability Coefficient is above 0.6, indicating that the reliability of the questionnaire is acceptable. The results of confirmatory factor analysis showed that the fitting index of each model was $\chi 2=904.619$, $\mathrm{df}=147$, RMSEA $=0.054<0.08$, TLI $=0.904>0.9$, and $\mathrm{CFI}=0.918>0.9$. All the main fitting indexes have reached the fitting requirements, which show that the fitting degree of the model and the data is better. The validity of the questionnaire is acceptable because the factor load values of all variables are above 0.3 and all reached significant levels.

Table 4. Fitting index of the subscale measurement model

\begin{tabular}{|c|c|c|c|c|c|c|c|}
\hline Variables & $\chi 2 / \mathrm{df}$ & GFI & AGFI & CFI & RMSEA & RMR & Cronbach's $\alpha$ \\
\hline Constructive Learning & 10.823 & 0.972 & 0.946 & 0.962 & 0.075 & 0.030 & 0.855 \\
\hline Destructive Learning & 3.347 & 0.998 & 0.990 & 0.994 & 0.037 & 0.013 & 0.693 \\
\hline Learning Behavior & 6.340 & 0.996 & 0.982 & 0.994 & 0.055 & 0.005 & 0.631 \\
\hline
\end{tabular}


The Cronbach's alpha reliability coefficient for each subscale ranges from 0.631 to 0.855 , and the reliability coefficient is generally considered to be higher than 0.7. Qin Xiaoqing (2004) has mentioned that in the domestic and foreign linguistics journals, there are also a few scales with low reliability because of the small number of items. Considering all these factors, each subscale in this study can be accepted.

\subsection{Correlation Analysis of Variables}

Correlation analysis is used to explore the relationship between major research variables, as shown in Table 5. The results show that there is a significant correlation between the major research variables. The correlation coefficient ranges from 0.063 to 0.589 . Destructive learning, employment pressure and the other four variables are negatively correlated (p $<0.01$ ), but the other correlations are significantly positively correlated $(\mathrm{p}<0.01)$.

Table 5. Correlation analysis

\begin{tabular}{|c|c|c|c|c|c|c|}
\hline & $\begin{array}{c}\text { Constructive } \\
\text { Learning }\end{array}$ & $\begin{array}{c}\text { Destructive } \\
\text { Learning }\end{array}$ & $\begin{array}{c}\text { Learning } \\
\text { Behavior }\end{array}$ & $\begin{array}{c}\text { Learning } \\
\text { Burnout }\end{array}$ & $\begin{array}{c}\text { Mutual } \\
\text { Influence }\end{array}$ & $\begin{array}{c}\text { Employment } \\
\text { Pressure }\end{array}$ \\
\hline Constructive Learning & 1 & & & & & \\
\hline Destructive Learning & $-0.250^{* *}$ & 1 & & & & \\
\hline Learning Behavior & $0.589^{*}$ & $-0.258^{* *}$ & 1 & 1 & & \\
\hline Learning Burnout & $0.274^{* *}$ & $-0.373^{* *}$ & $0.252^{* *}$ & & \\
\hline Mutual Influence & $0.153^{* *}$ & $-0.116^{* *}$ & $0.132^{* *}$ & $0.082^{* *}$ & 1 & \\
\hline Employment Pressure & $-0.080^{* *}$ & $0.128^{* *}$ & $-0.063^{* *}$ & $-0.124 * *$ & $-0.108^{* *}$ & 1 \\
\hline
\end{tabular}

\subsection{Regression Analysis}

Regression analysis is used to further explore constructive learning, destructive learning and the impact of classmates on learning behavior. The results of the regression analysis are shown in Table 6 . The regression equation is significant $(\mathrm{F}=$ $\left.331.120, \mathrm{R}^{2}=0.362, \mathrm{p}<0.01\right)$. Constructive learning positively predicts learning behavior $(\beta=0.555, \mathrm{t}=27.954, \mathrm{p}<0.01)$ and destructive behavior significantly negatively predicts learning behavior $(\beta=-0.115, \mathrm{t}=-5.827, \mathrm{p}<0.01)$. The mutual influence does not significantly predict the learning behavior $(\beta=0.034, \mathrm{t}=1.761, \mathrm{p}>0.05)$. Constructive learning behavior plays a positive role in learning. Destructive learning has a negative effect. The impact of class influence on English learning is not obvious, as it is difficult to judge.

Table 6. Regression analysis on learning behavior

\begin{tabular}{|c|c|c|c|c|c|}
\hline & $\beta$ & $\mathrm{t}$ & $\mathrm{p}$ & $\mathrm{F}$ & $\mathrm{R}^{2}$ \\
\hline Constructive Learning & 0.555 & 27.954 & 0.000 & \multirow{3}{*}{$\begin{array}{c}\mathrm{F}=331.120, \\
\mathrm{P}<0.01\end{array}$} & \multirow{3}{*}{$\begin{array}{c}\mathrm{R}^{2}=0.362, \\
\mathrm{P}<0.01\end{array}$} \\
\hline Destructive Learning & -0.115 & -5.827 & 0.000 & & \\
\hline Mutual Influence & 0.034 & 1.761 & 0.078 & & \\
\hline
\end{tabular}

Using regression analysis to further explore the constructive learning, destructive learning and the impact of classmates on learning burnout, the results of regression analysis are shown in Table 7 . The regression equation is significant $\left(\mathrm{F}=119.651, \mathrm{R}^{2}=0.170, \mathrm{p}<0.01\right)$. Destructive learning significantly negatively predicts learning burnout $(\beta=-0.115$, $\mathrm{t}=-$ 5.827, $\mathrm{p}<0.01)$ and learning behavior significantly positively predicts learning burnout $(\beta=0.164, \mathrm{t}=7.294, \mathrm{p}<0.01)$. Employment pressure significantly positively predicts learning burnout $(\beta=-0.072, \mathrm{t}=-3.287, \mathrm{p}<0.01)$.

Table 7. Regression analysis on learning burnout

\begin{tabular}{|c|c|c|c|c|c|}
\hline & $\beta$ & $\mathrm{t}$ & $\mathrm{p}$ & $\mathrm{F}$ & $\mathrm{R}^{2}$ \\
\hline Destructive Learning & -0.321 & -14.16 & 0.000 & $\begin{array}{c}\mathrm{F}=119.651, \\
\mathrm{P}<0.01\end{array}$ & $\begin{array}{c}\mathrm{R}^{2}=0.170, \\
\mathrm{P}<0.01\end{array}$ \\
\hline
\end{tabular}

\subsection{Structural Equation Modeling}

Structural equation modeling is used to further explore the relationship of the major research variables and the resulting final model is shown. The main fitting indexes of this model are: $\chi 2=904.619$, $\mathrm{df}=147, \mathrm{RMSEA}=0.054<0.08, \mathrm{TLI}=0.904>0.9$, $\mathrm{CFI}=0.918>0.9$, which reach the fitting requirements. It means that the model is acceptable. As shown below in Figure 1.

The path coefficients of the major variables are shown in Table 8. Mutual influence can significantly predict learning behavior $(\beta=0.048, \mathrm{t}=2.269, \mathrm{p}<0.05)$, and employment pressure can significantly predict learning burnout $(\beta=-0.068, \mathrm{t}=-$ $3.158, \mathrm{p}<0.01)$. 


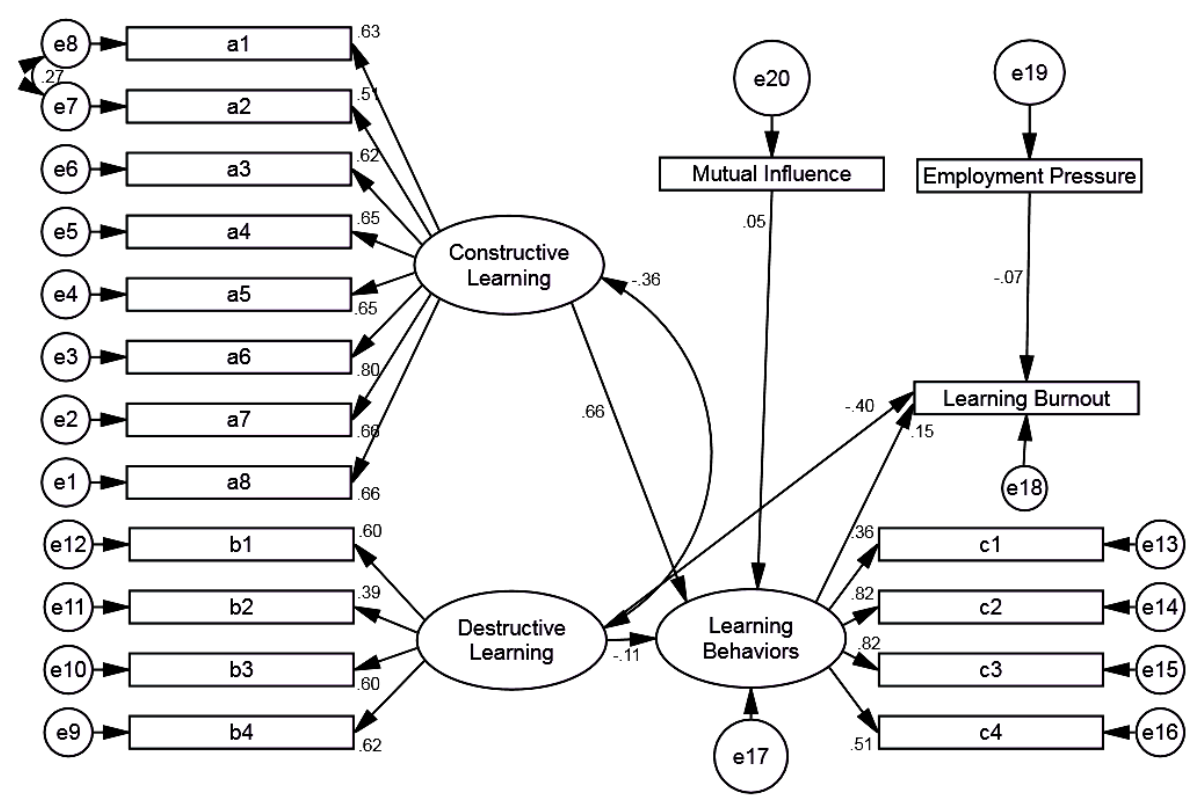

Figure 1. Structural equation modelling

In addition, construction learning can positively predict learning behavior $(\beta=0.655, \mathrm{t}=15.519, \mathrm{p}<0.01)$, destructive behavior can negatively predict learning behavior $(\beta=-0.109, \mathrm{t}=-3.706, \mathrm{p}<0.01)$, destructive behavior can negatively predict learning burnout $(\beta=-0.403, \mathrm{t}=-11.796, \mathrm{p}<0.01)$, and learning behavior can positively predict learning burnout $(\beta=0.149, \mathrm{t}=5.396, \mathrm{p}<0.01)$. The results show that learning behavior plays a mediating role among constructive learning, destructive learning and learning burnout. Among them, learning behavior plays a mediating role between constructive learning and learning burnout. The median effect value is $9.76 \%$. In the mediating role of learning behavior between destructive learning and learning burnout, the ratio of intermediary effect to the total effect is $3.96 \%$

\begin{tabular}{|c|c|c|c|c|c|c|}
\multicolumn{9}{|c|}{ Table 8. Path coefficient in structural equation model } \\
\hline $\begin{array}{c}\text { Dependent } \\
\text { Variable }\end{array}$ & & Independent Variable & Estimate & S.E. & C.R. & \multirow{2}{*}{ P } \\
\hline \multirow{2}{*}{$\begin{array}{l}\text { Learning } \\
\text { Behavior }\end{array}$} & $<---$ & Constructive Learning & 0.655 & 0.02 & 15.519 & $* * *$ \\
\cline { 2 - 7 } & $<---$ & Destructive Learning & -0.109 & 0.014 & -3.706 & $* * *$ \\
\cline { 2 - 7 } & $<---$ & Mutual Influence & 0.048 & 0.018 & 2.269 & 0.023 \\
\hline \multirow{2}{*}{ Learning } & $<---$ & Employment Pressure & -0.068 & 0.018 & -3.158 & 0.002 \\
\cline { 2 - 7 } Burnout & $<---$ & Learning Behavior & 0.149 & 0.036 & 5.396 & $* * *$ \\
\cline { 2 - 7 } & $<---$ & Destructive Learning & -0.403 & 0.021 & -11.796 & $* * *$ \\
\hline
\end{tabular}

\section{Conclusions}

Through the data analysis and model construction in this study, we find that learning behaviors, including constructive learning behavior and destructive learning behavior, play an important role in English effective learning in higher vocational colleges. For higher vocational students, learning behavior is an indispensable and important factor in the progress of English learning. The effect of learning behavior on English effective learning has good structural validity and structural reliability. It is of great theoretical and practical significance to incorporate constructive learning behavior and destructive learning behavior into the category of learning effectiveness. As shown through difference test, correlation analysis, regression analysis and structural equation modeling, although learning behavior has different influences on employment pressure, mutual influence and learning burnout, it does play a positive or negative role in effective English learning.

Although a number of important factors are considered in the correlation study of the influence of learning behavior on English effective learning, further expansion and verification of other factors are still needed. The impact of learning behavior on effective learning requires a wider and broader data analysis and case studies, so more scientific and reasonable conclusions can be obtained. 


\section{Acknowledgements}

Thanks to Associate Professor Xia Liu, the correspondent of this paper. This paper was supported by Hainan Province Education Science Planning Leading Group Office. Subject Name: Error Analysis of College English Writing Driven by Big Data and Computer Automatic Feedback Scheme (No. QJY13516005).

\section{References}

1. Q. H. Ming and M. R. Gu, "Effective Learning Is the Starting Point and Ownership of Effective Teaching", Journal of the Chinese Society of Education, vol. 5, pp. 32-36, 2015

2. X. Q. Qin, "Quantitative Data Analysis in the Study of Foreign Language Teaching”, Wuhan: Huazhong University of Science and Technology Press, 2004

3. K. S. Sun, K. Wang, and Z. S. Chen, "Research on the Relationship Between Multiple-Goal Orientation and Destructive Behavior in Studying Physical Education", Theory and Practice of Education, vol.36, pp60-62, 2017

4. Taraban R, Kerr M and Rynearson K, "Analytic and Pragmatic Factors in College Students' Metacognitive Reading Strategies", Reading Psychology, vol.25, no.2, pp.67-81,2004

5. S. R. Wang, "An Interpretation of the Main Points of Guidelines on College English Teaching", Foreign Language World, no.3, 2016

6. X. B. Wei, "Structural Analysis on College Students' Achievement Goal Orientation, Learning Anxiety and Self-Access Learning Behavior", Foreign Language World, no.4, 2014

7. Z. Yang, and A. L. Wang, "Factors Influencing Students' Effective Learning and Approaches to Its Realization", Theory and Practice of Education, vol.36, no.10, pp.56-59,2016

Lei Chen graduated from the College of Public Administration, Central China Normal University, with a Master's Degree. He entered Sanya Aviation \& Tourism College as an English teacher in 2007. Now, he is an Associate Professor of the School of Humanities \& Social Sciences. His current research interests include English teaching, cross-cultural communication and statistical linguistics analysis.

Xia Liu received his Bachelor's Degree from Sichuan Normal University, Chengdu, China, in 2006. He entered Sanya Aviation \& Tourism College as a computer teacher in 2006. Now, he is an Associate Professor of the School of Humanities $\&$ Social Sciences. He is a member of the China Computer Federation and a member of IEEE. His current research interests include data mining and analysis as well as computer application.

Qinghui Zhu received her Master's Degree from Central China Normal University. Now, she works in the College of Foreign Languages, Hainan University, Haikou, China. Her current research interests include translation practice and English linguistics. 